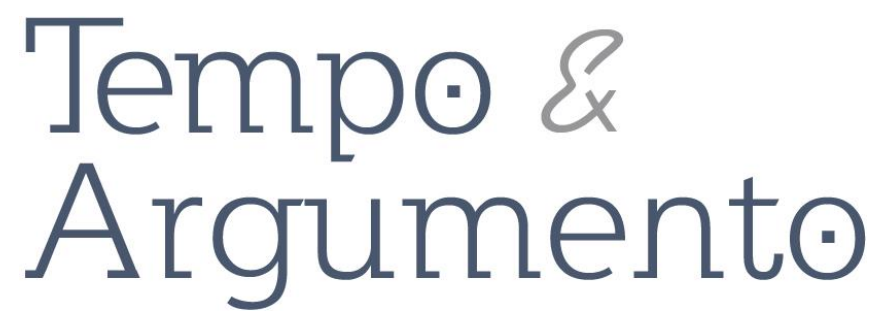

\title{
Ambiguidades do tempo na maré dos Direitos Humanos
}

Resenha da obra:

BEVERNAGE, Berber. História, memória e violência de Estado: tempo e justiça. Tradução de André Ramos, Guilherme Bianchi. Serra: Editora Milfontes - Mariana: SBTHH, 2018. 364p.

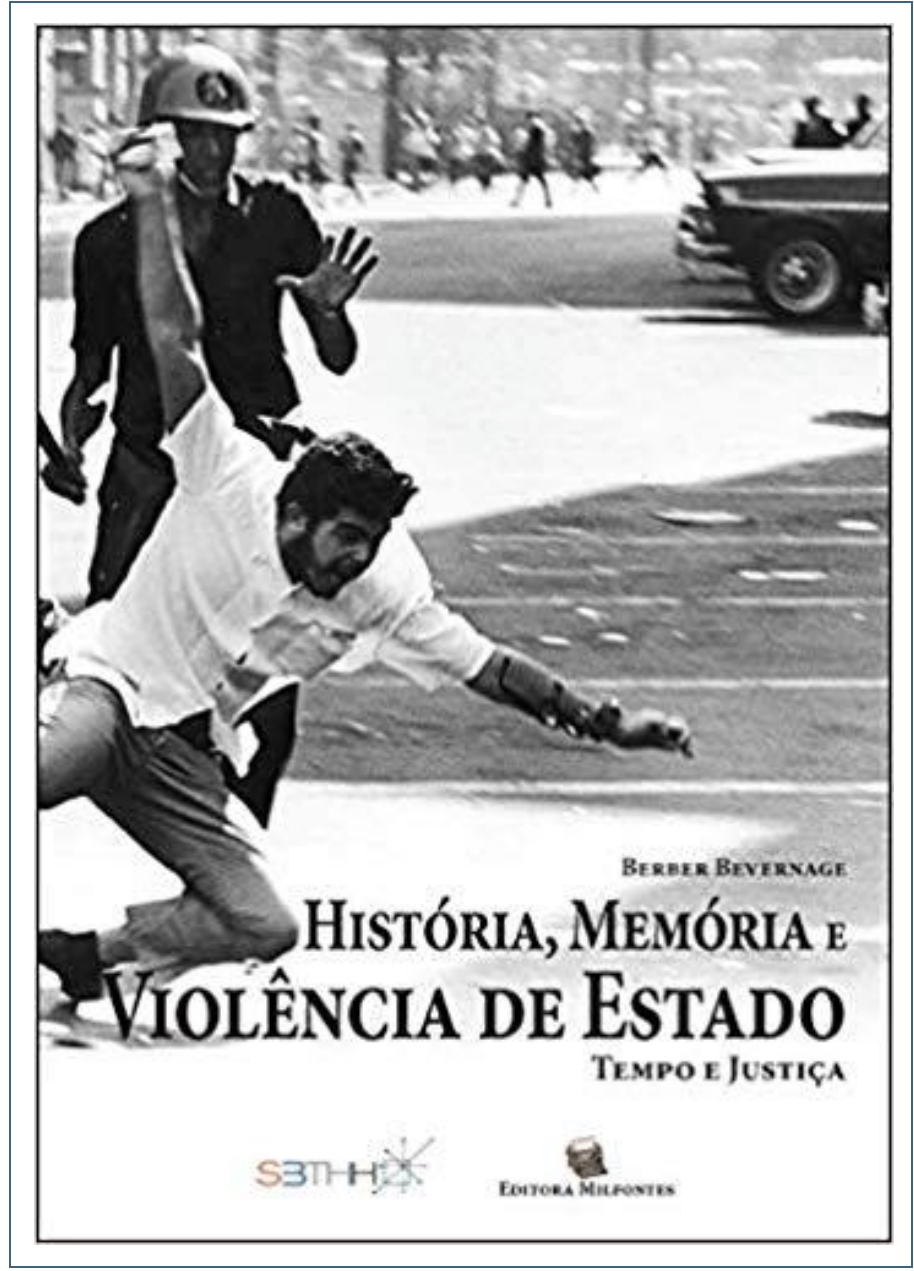

Autor da resenha

Nashla Dahas Gomozias
Doutora em História Social pela
Universidade Federal do Rio de
Janeiro (UFRJ). Estágio Pós-Doutoral
na Universidade do Estado de Santa
Catarina (UDESC).
Florianópolis, SC - BRASIL
nashladahas@hotmail.com
orcid.org/oooo-0001-5384-4715

Para citar esta resenha:

BEVERNAGE, Berber. História, memória e violência de Estado: tempo e justiça. Tradução de André Ramos, Guilherme Bianchi. Serra: Editora Milfontes - Mariana: SBTHH, 2018. 364p. Resenha de: DAHAS, Nashla. Ambiguidades do tempo na maré dos Direitos Humanos. Revista Tempo e Argumento, Florianópolis, v. 11, n. 27, p. 509 - 516. maio/ago. 2019.

DOI: $10.5965 / 2175180311272019509$

http://dx.doi.org/10.5965/2175180311272019509 
"Por que é tão difícil entender o passado assombroso e irrevogável na perspectiva da historiografia acadêmica e do pensamento histórico moderno ocidental em geral?" A pergunta que guia História, Memória e Violência de Estado: tempo e justiça, de Berber Bevernage (2018), pressupõe a angústia da incompletude e do inacabamento (MBEMBE, 2014), da indeterminação e instabilidade do objeto “tempo presente" (DELACROIX, 2018). O autor nos oferece um mergulho na história da crítica à noção de tempo construída pela modernidade para mostrar toda a sua potência e enraizamento enquanto engenhosa forma de "não ver" certos mundos, grandemente incorporada pela disciplina histórica. Por entre as brechas desse olhar pretensamente universal, América Latina e África emergem como que alçadas à categoria de experiências (i)morais - porque marcadas pela violência e injustiça -, da luta política que marca o século XXI periférico: o direito ao tempo.

Entre as referências mais conhecidas pelo universo acadêmico brasileiro dedicado à História do Tempo Presente e que constituem a base da argumentação de Tempo e Justiça estão o crítico literário alemão Hans Gumbrecht e o historiador francês François Hartog. Por caminhos diferentes, ambos chamam atenção para o crescimento ao longo do século XX de uma nova sensibilidade temporal marcada por uma assimétrica concentração na esfera de um presente repleto de simultaneidades (GUMBRECHT, 2014), demarcando a emergência de um novo "regime de historicidade" chamado presentista (HARTOG, 2013). No interior dessa discussão, o livro apresenta os anos de 1980 como período de evidência dos embates entre formas distintas de experienciar o tempo (com suas diferentes articulações entre passado, presente e futuro), expressas pelo desaparecimento da linguagem do esquecimento e da anistia do vocabulário político global.

Trata-se do contexto de emergência da justiça de transição e das comissões da verdade como possibilidades institucionais de instaurar um recomeço democrático em sociedades pós-conflito a partir do estabelecimento da verdade e baseando-se nos testemunhos - "memórias reveladas" -, assim como no discurso histórico. O campo da chamada justiça de transição - ainda pouco frequentado pelos(as) historiadores(as) brasileiros - é discutido a partir das definições da especialista argentina em direitos 
humanos Ruti Teitel. Segundo a autora, o contexto de transição política e social cria a necessidade de um novo repertório de mecanismos de justiça. O dilema das comissões de transição, contudo, recairia sobre a inescapável escolha entre a paz construída sobre a supressão pública das memórias das vítimas, ou uma justiça que traduz a vingança.

Um dos sintomas identificados por Berber Bevernage no percurso da virada cultural a respeito do esquecimento é a sensação de uma "febre mundial por reparações e desculpas" vivenciada mais evidentemente desde os anos 2000 e apontada por cientistas sociais como substituto da elaboração de visões de futuro na política contemporânea. O autor abre, contudo, um amplo campo de estudos ao apontar a face mais ambígua e conservadora das respostas encontradas no âmbito da multiplicação do chamado "dever de memória”: as comissões da verdade, em geral, reagem à mudança social de percepção sobre o tempo e promovem um uso performativo do discurso histórico que visa impor a todo o custo a consciência moderna sobre o tempo tradicionalmente entendido como irreversível. Essa "política do tempo" tem como resultado não necessariamente consciente uma atitude institucional democrática que estimula as vítimas ou seus parentes a "deixar o passado para trás" sempre que não possam alcançar a justiça.

Pesquisador pós-doutorando na Universidade de Ghent, na Bélgica, Bevernage discute em sua tese de doutorado - da qual resulta o livro -, a hipótese contraintuitiva de que o conceito de tempo histórico, em geral, empregado por historiadores(as) profissionais, tem muito mais em comum com o ponto de vista dos perpetradores dos crimes, do que com aqueles de suas vítimas. Ou seja, a justiça de transição tem se consolidado como o palco para um embate entre diferentes regimes de historicidade no qual o passado continua sendo concebido pelos(as) historiadores(as) como irreversível. A explicação para esse descompasso em relação às simultaneidades sociais estaria numa tradição de conceitualizações de tempo e historicidade que têm restringido um semnúmero de pesquisadores(a) a compreender, reconhecer ou mesmo imaginar o passado como "irrevogável”" - impedindo-os(as), assim, de senti-lo ou vivenciá-lo como parte do presente.

\footnotetext{
${ }^{1} \mathrm{O}$ conceito de passado irrevogável utilizado por Berber Bevernage é tributário das reflexões do filósofo
} 
Segundo Bevernage, ao incorporar a ideia de que o tempo histórico é irreversível como uma baliza epistêmica naturalizada, os(as) modernos(as) pensadores(as) ocidentais ou ocidentalizados(as) tornam-se incapazes de assegurar dignidade moral e intelectual às reivindicações comuns das vítimas e sobreviventes de que o passado persiste e assombra o presente. Nesse caso, o desfio de uma ética renovada da história consistiria em atribuir aos discursos das vítimas a mesma relevância concedia à historiografia para pensar o tempo.

O livro divide-se em duas partes quase autônomas. Na primeira, mais empírica, são apresentadas as semelhanças entre os discursos das autoridades ligadas à última ditadura argentina (1976-83), ao Apartheid na África do Sul (1948-94) e à guerra civil em Serra Leoa, na África Ocidental (1991-2002), e as narrativas dos membros e representantes das respectivas Comissões realizadas ao fim oficial daqueles conflitos. Simultaneamente, somos instigados a acompanhar a inconformidade e insubordinação de movimentos civis contra a imposição de encerramento do período de violações como passado. 0 esquecimento consciente e a subordinação da justiça retrospectiva a uma política orientada pelo presente transicional e por um futuro "reconciliado" também aparecem nos discursos de cientistas e pensadores(as) ligados à defesa da democracia e da emancipação, como é o caso da filósofa política norte-americana Jean Bethke Elshtain, que sustenta, além do direito à verdade e à memória, o recurso a um "esquecimento voluntário" para que as violações nunca mais aconteçam. Dos três casos de Comissões da Verdade analisados, o processo argentino é aquele com o qual o autor parece mais envolvido, talvez porque é exatamente o capítulo que configura mais consistentemente seus argumentos. É, sem dúvida, o ponto alto da obra.

$\mathrm{Na}$ segunda parte do livro - teórica -, seguimos o percurso da compreensão moderna de tempo como "tempo histórico", através das ideias centrais dos principais críticos da história historicista Fernand Braudel, R. G. Collingwood, Ernst Bloch e Louis Althusser. Berber Bevernage procede a uma crítica da noção de tempo absoluto, vazio e homogêneo, da descrição historicista da mudança histórica, da crença modernista em uma estrita divisão entre passado e presente e da naturalização da rejeição secularizada

francês Vladimir Jankélévitch sobre temporalidade: JANKÉLÉVITCH, V. L'irréversible et la nostalgie. Paris, Flammarion, 1974. 
de "tempos superiores" (p. 215), procurando oferecer, nos capítulos finais, uma saída para os problemas que apresenta. Nesse ponto, são mobilizados(as) autores(as) como o norte-americano Dominick LaCapra, o alemão Jörn Rüsen, além da fundamental contribuição da historiadora polonesa Ewa Domanska para a compreensão de uma relação próxima entre luto e historiografia. Por fim, entram em cena a espectralidade derridiana e a categoria de luto como bases intelectuais potencialmente apropriadas para a construção de perspectivas "mais inclusivas e democráticas da história”.

No chamado "documento final”, emitido em 28 de abril de 1983, os militares que dirigiram a última ditadura argentina expressam sua compreensão da "guerra à subversão" e falam sobre memória e reconciliação num tom que, segundo Berber Bevernage, dificilmente pode ser discernido daqueles utilizados pelas Comissões da Verdade:

a reconciliação é o difícil começo de uma era de maturidade e responsabilidade assumida com realismo por todos. As cicatrizes são uma memória dolorosa, mas também o cimento de uma poderosa democracia, de pessoas unidas e livres. [...] Apenas o tribunal da história poderá determinar exatamente a quem pertence a responsabilidade direta pelos métodos injustos e as mortes inocentes". (Documento final sobre a guerra contra a subversão e o terrorismo, p. 98)

Seguindo a mesma lógica de encerramento e reconciliação, os sucessivos governos democráticos argentinos desenvolveram um discurso semelhante ao militar segundo o qual o passado era algo que devia ser deixado para trás:

Ao final do seu mandato, [Raúl] Alfonsín afirmou que a Argentina não poderia sobreviver se não se libertasse do fardo do passado. Do mesmo modo, Menem encobriu suas infames leis de anistia em um discurso histórico que falava sobre o "fechamento de capítulos" e afirmou que a anistia visava a "tarefa árdua e delicada de fechar etapas amargas e dolorosas na vida nacional argentina. (BEVERNAGE, p. 98)

Nesse percurso, a Comissão Nacional sobre o Desaparecimento de Pessoas (CONADEP) foi estabelecida por decreto em dezembro de 1983 e durante nove meses tomou testemunhos, identificou e visitou um grande número de centros secretos de detenção, além de ter organizado algumas exumações de valas comuns e sepulturas 
anônimas. Também realizou buscas por pessoas não identificadas em prisões e instituições psiquiátricas. Em setembro de 1984, a comissão entregou 50.000 páginas de documentação ao presidente Alfonsín, e publicou um relatório em formato de livro, omitindo os nomes dos perpetradores, intitulado Nunca Más. O tema pedagógico de todo o trabalho se tornou um slogan internacional das políticas de memória e uma bandeira de muitos movimentos de direitos humanos: lembrar para que não se repita, para que nunca mais aconteça. A única e importante exceção à cooperação com a CONADEP foi o movimento Madres de Plaza de Mayo que insistiu na luta pela "aparição com vida" (p. 95)

Deste ponto em diante, Bevernage reconstrói o cenário agoniante de progressivo isolamento das Madres diante de divisões internas e do posicionamento dos órgãos nacionais e internacionais considerados humanistas, favoráveis às chamadas Políticas públicas de Memória e Verdade. O autor se pergunta reiteradamente como entender as posições radicais sobre o legado do terror de Estado. Como lidar com a linguagem espectral manifestada em expressões como "aparición com vida" ou "desaparecidos para siempre"? As respostas começam a surgir no compasso do próprio desenvolvimento do movimento de mães que, em 1999, chega a criar a Universidad Popular Madres de Plaza de Mayo (UPMPM), oferecendo cursos e palestras sobre os distintos usos da história que vão da "história como uma relação ativa com o passado" até a "história como um discurso de poder hegemônico" (p. 102).

Emblemático, entretanto, parece ter sido o discurso da líder mais conhecida das Madres, Hebe de Bonafini, em 1995, no qual ela retoma as palavras provocativas do escritor Eduardo Galeano: “A morte não existe”. De acordo com Bevernage, a evocação buscava alçar o "desaparecimento" - como modalidade repressiva da ditadura argentina entre 1976 e 1983 - a uma condição subjetiva das sobreviventes e familiares, e a um estatuto de luta política intergeracional em pleno vigor. Isso explica que as Madres falem de seus filhos desaparecidos no tempo presente, que rejeitem reparações econômicas e placas de identificação, monumentos ou exumações. Que rechacem o Nunca Más, acusando-o de implicitamente igualar o terror de Estado com a violência das guerrilhas de esquerda. 
Menos densos são os capítulos dedicados à Comissão da Verdade e Reconciliação da África do Sul (TRC, 1996-2003), e à saída de duas vias em Serra Leoa na qual uma Comissão da Verdade e um tribunal de guerra operaram lado a lado. No primeiro caso, apesar da inovação jurídico-política que significou a anistia condicionada à revelação completa da verdade histórica, de acordo com Bevernage, como na crítica das Madres à CONADEP, e como em grande parte dos discursos ligados à Justiça de Transição, a TRC recorreu ao discurso histórico com a finalidade de restaurar ou impor o tempo histórico irreversível e "reforçar a fronteira modernista entre passado e presente, ameaçada por um tipo particular de memória que resiste à cronologia e se nega a deixar o passado passar" (p. 113). Essa memória circula e pressiona especialmente através do grupo Khulumani - que significa expressar-se em isiZulu, o único movimento social autônomo pós-Apartheid que representa as vítimas e sobreviventes da violência do Apartheid e para o qual "elaborar uma história da luta significa escrever uma história sobre uma luta que não acabou" (p. 137). Seu principal apelo à sociedade sul-africana consiste na negação da distância entre o passado e o presente: “O passado não enterra o passado” (p. 138).

No caso de Serra Leoa, Bevernage retoma o discurso do presidente Alhaji Kabbah, em abril de 2003 - no qual o dirigente afirma que mais do que revelar a verdade, 0 objetivo mais importante da Comissão da Verdade era sua função terapêutica que deveria conduzir à reconciliação nacional -, para evidenciar o que chama de uma "vontade de modernidade" fortemente pronunciada; uma busca pelo progresso e uma vontade de "mover o país para frente" afastando-se do passado sombrio (p. 145). Segue-se a descrição de uma sucessão de acontecimentos violentos que caracterizaram a guerra civil na região, incluindo violação das mulheres locais e brutalidade sobre civis. Pode-se dizer que a abordagem do historiador é marcada pela percepção de uma realidade considerada trágica à luz de uma esperança eminentemente democrática. Suas conclusões sobre os dois exemplos africanos apontam para a ligação entre verdade histórica e a construção da nação dada como auto-evidente e nunca discutida socialmente, de maneira que o uso performativo do discurso histórico acaba por funcionar como uma tentativa de exorcismo do passado assombroso. 
Tempo e Justiça é obra multidisciplinar de leitura fluida que oferece grande volume de referências e documentos transnacionais sobre os temas mais sensíveis daquilo que se convencionou chamar de Tempo Presente. Sua publicação em português é um convite intrigante e indispensável a uma produção historiográfica descentrada tecida de memória e subjetividade, e sustentada por noções de tempo nascidas da violência, do luto e do desaparecimento.

\section{Referências}

DELACROIX, Christian. A história do tempo presente, uma história (realmente) como as outras? Revista Tempo e Argumento, Florianópolis, v. 10, n. 23, p. 39 - 79, jan./mar. 2018. Tradução de Fernando Coelho. Título original: L'histoire du temps présent, une histoire (vraiment) comme les autre. $\mathrm{T}$

GUMBRECHT, Hans Ulrich. Depois de 1945: latência como origem do presente. Trad. Ana Isabel Soares. São Paulo: Ed. UNESP, 2014.

HARTOG, François. Regimes de historicidade: presentismo e experiências do tempo. Belo Horizonte: Autêntica, 2013, 272 p.

MBEMBE, Achille. Crítica da Razão Negra. Antígona, Lisboa, 2014.

Universidade do Estado de Santa Catarina - UDESC Programa de Pós-Graduação em História - PPGH Revista Tempo e Argumento Volume 11 - Número 27 - Ano 2019 tempoeargumento@gmail.com 